\title{
ECONOMY-WATER NEXUS IN AGRICULTURAL SECTOR: DECOMPOSING DYNAMICS IN WATER FOOTPRINT BY THE LMDI
}

\author{
Weihua SU${ }^{1}$, Sibo CHEN $^{1}$, Tomas BALEŽENTIS ${ }^{2}$, Ji CHEN ${ }^{1 *}$ \\ ${ }^{1}$ College of Statistics and Mathematics, Zhejiang Gongshang University, Hangzhou 310018, China \\ ${ }^{2}$ Lithuanian Institute of Agrarian Economics, A. Vivulskio g. 4A-13, 03220 Vilnius, Lithuania
}

Received 15 May 2019; accepted 20 October 2019

\begin{abstract}
Traditional economic activities induce environmental pressures. In order to ensure sustainable economic growth, one needs to decouple it from the environmental pressures. Sustainable growth of the agricultural sector is topical in the sense that economic activity supports rural populations, whereas the resulting environmental pressures may affect diverse groups of population. Thus, the analysis of water footprint related to crop farming is important in the sense of efficient resource use and sustainable development of agriculture in general. In this paper, we focus on Lithuanian crop farming and the related green and grey water footprints. Specifically, we decompose the changes in the water footprints during 2000-2016 by exploiting the Logarithmic Mean Divisia Index. Due to the expansion of the areas harvested, the scale effect appeared as an important driver of growth in green and grey water footprints. The shifts in spatial distribution of area harvested virtually had no influence on the dynamics in either of the water footprints. The crop-mix effect was much higher for the grey water footprint (51\% over the period of 2000-2015) than it was the case for the green water footprint $(21 \%)$. The yield growth induced growth in both green and grey water footprints.
\end{abstract}

Keywords: water economics, economy-water nexus, water footprint, Index Decomposition Analysis, Logarithmic Mean Divisia Index, crop farming, Lithuania.

JEL Classification: C43, Q15, Q25.

\section{Introduction}

The focus on economic growth and sustainability has instigated the emergence of the concept of sustainability. Agricultural sector also requires solutions for sustainable growth (Zilberman, 2014; Zilberman et al., 2018; Wang et al., 2019; Lin et al., 2019; Fedulova et al., 2019; Serban et al., 2017). Sustainable use of resources appears as an important direction for development of the whole economy and particular sectors (Song et al., 2019; Miao et al., 2019). The primary sector is responsible for sustainable use of multiple resources, both ma-

${ }^{\star}$ Corresponding author. E-mail: chenji810404@zjgsu.edu.cn 
terial and human ones (Toma et al., 2017). Water appears an important resource needed for both agricultural production and human needs (Aznar-Sánchez et al., 2019; Miglietta et al., 2018; Rosegrant et al., 2013; Chaudhry \& Barbier, 2013; Arto et al., 2016). Hence, the foodenergy-water nexus appears as a focal topic in the context of sustainability (Tian et al., 2018; Cai et al., 2018). The United Nations World Water Development Report identified multiple threats to water resources and their linkages to the other ecosystems (UN-Water, 2018).

In the context of the increasing concerns on the resource efficiency, water economics has become a topical issue (Drysdale \& Hendricks, 2018; McCarl \& Hertel, 2018; Sears \& Lawell, 2019). The strategies for sustainable use of water in the context of crop production and agriculture in general have been outlined in the European Union (Richard et al., 2018; Papadimitriou et al., 2019; Tsolakis et al., 2018) and the other regions (Chaudhry, 2018; Bae \& Dall'erba, 2018; Xu \& Lowe, 2018). In order to adapt to the climate change, the modelling of water systems and economic activities is needed (Dainys et al., 2019; Schönhart et al., 2018).

The sustainability of water use in agriculture is related to multiple factors. The natural constraints and the resulting crop-mix imply the need for application of different technologies across different parts of the world. The economic conditions determine the demand for different agricultural products and trade flows which, in turn, affect the water consumption. The differences in the real prices of different crops (or other agricultural products) also determine the production structure, revenue, and use of water along with the other resources. Thus, there have been a number of theoretical approaches and empirical applications developed in the domain of sustainable water use in agriculture (Velasco-Muñoz et al., 2018a, 2018b; Aznar-Sánchez et al., 2018).

In order to properly assess the impacts of production systems on the use of water resources, a framework involving dedicated measures and analytical tools is required. As regards the measures used for this end, the water footprint concept developed by Hoekstra et al. (2011) provides a comprehensive approach towards the measurement of the demand for water resources. By disaggregating the water footprint into green, grey and blue footprints, one is able to track the use of water from the viewpoint of precipitation water, pollutant assimilation and groundwater or surface water, respectively. The latter indicator can be applied from production and consumption perspectives. There have been a number of studies applying the water footprint for different issues. Miglietta et al. (2018, 2017a) applied the grey water footprint for analysis of water pollution in different sectors in Italy. D'Ambrosio et al. (2018) applied the water footprint of crop farming in a Mediterranean watershed. De Girolamo et al. (2019) developed a framework for dealing with uncertainties in the measurement of the parameters determining the water footprint and applied the approach for the case of durum wheat production in the Rio Mannu Basin (Italy). Miglietta et al. (2017b) proposed the environmental Kuznets curve involving water footprint and applied it for a sample of 94 countries. Zhao et al. (2014) decomposed the water footprint with regards to population, affluence, urbanization level, and diet structure for Chinese agricultural sector.

Environmental pressures, including the water footprint, are influenced by a number of different factors. These factors are both structural ones and extensive ones (e.g. scale effect). Preparing effective measures for mitigation of environmental pressures calls for identification of the underlying factors. The index decomposition analysis (IDA) has been applied as a tool for isolating the effects of multiple drivers of the environmental pressures (Ang, 2005, 2015). Among different approaches of the IDA, the Logarithmic Mean Divisia Index (LMDI) has appeared as an effective technique for attributing the changes in the water footprint to 
explanatory factors. Indeed, it also follows the theoretical requirements for such methods including time reversal and perfect decomposition. The LMDI has been applied for the analysis of water footprint dynamics at the international (Zhuo et al., 2016), national (Li et al., 2017; Zhao \& Chen, 2014) and regional (Xu et al., 2015; Zhao et al., 2017) levels.

Lithuanian agriculture was affected by the Common Agricultural Policy of the European Union. In particular, the crop farming saw an increasing share in the total agricultural output. This has caused changes in environmental pressures besides economic impacts. Thus, it is important to identify the underlying trends and factors in water footprint for Lithuanian crop farming. In this paper, we focus on the green and grey water footprints as the irrigation systems (represented by the blue water footprint) are not generally applied in Lithuania. The green water footprint measures the requirement for water from precipitation. The grey water footprint measures the requirement of water for dilution of agrochemicals applied. We use the county-level data for different crops. The period covered is 2000-2016. The LMDI is applied for the decomposition of changes in the water footprints.

\section{Methods and data}

This section presents the major methodological approaches taken in order to isolate the effects of the dynamics in the water footprint of Lithuanian crop farming. First, the IDA identity is defined to explain the relationships between the water footprint and agricultural activities. Second, the LMDI approach is adapted for the case of the water footprint analysis. The discussed approach allows one to analyse the changes in the water footprint from different perspectives and levels of aggregation.

\subsection{IDA identity}

In this paper, we consider the green and grey water footprints of Lithuanian crop farming. Therefore, the two IDA identities are established for each footprint type. The water footprint methodology (Mekonnen \& Hoekstra, 2010) suggests the footprint is dependent on the yield. Therefore, we account for extensive and intensive changes underlying the crop farming. Here, by intensive factors we mean that the water footprint might be altered without actually adjusting the scale of crop farming. On the contrary, extensive factors capture the effects of changes in the scale of crop farming.

The extensive factor is the area effect, which indicates the additional requirement or savings in green or grey water due to changes in the utilized agricultural area (with other factors remaining fixed). However, the crop structure varies across regions and time thus making the virtual yields varying across space and time. In order to account for such dynamics, we further consider some intensive factors.

We model the water footprints (grey and green) by considering the areas harvested, yields and footprint factors at the county level. Let there be indexes $i=1,2, \ldots, I$ and $j=1,2, \ldots, J$ for counties and crops respectively. Each crop is associated with a corresponding carbon footprint factor, $f_{j}$ (again, these factors vary for green or grey footprint). Let the total area harvested in hectares be denoted by $A$ and the total are harvested in county $i$ denoted by $a_{i}$. The area harvested under crop $j$ in county $i$ is denoted by $a_{i j}$. Obviously, $A=\sum_{i=1}^{I} a_{i}=\sum_{i=1}^{I} \sum_{j=1}^{J} a_{i j}$. Crop yields vary across the counties as we consider crop output in tonnes denoted by $y_{i j}$. 
Therefore, water footprint can be calculated by applying the following relationship:

$$
F=\sum_{i=1}^{I} \sum_{j=1}^{J} f_{j} \frac{y_{i j}}{a_{i j}} \frac{a_{i j}}{a_{i}} \frac{a_{i}}{A} A=\sum_{i=1}^{I} \sum_{j=1}^{J} f_{j} Y_{i j} A_{i j} A_{i} A,
$$

where $F$ is the water footprint (grey or green one) and $Y_{i j}, A_{i j}$, $A_{i}$ and $A$ represent yield, cropmix, spatial distribution and scale effects respectively. Therefore, we account for changes in pure and aggregate crop yields. The former ones are related to short-term environmental shocks, improved farming practices and varieties, whereas the latter ones are outcomes of structural changes which are directed by economic and long-term environmental factors.

The IDA identity presented in Eq. (1) is a static one. As we are interested in the dynamics in the water footprints, we can establish a dynamic setting by introducing the underlying calculations for carbon footprint during time period $t$ as follows:

$$
F^{t}=\sum_{i=1}^{I} \sum_{j=1}^{J} F_{i j}^{t}=\sum_{i=1}^{I} \sum_{j=1}^{J} f_{j} Y_{i j}^{t} A_{i j}^{t} A_{i}^{t} A^{t} .
$$

Note that we assume carbon factors are fixed for the period covered in the analysis. Thus, IDA can be applied to decompose the change in the water footprint as follows:

$$
\Delta F=F^{T}-F^{0}=\Delta F_{\text {yield }}+\Delta F_{\text {crop }}+\Delta F_{\text {distribution }}+\Delta F_{\text {scale }},
$$

where indexes $T$ and 0 denote that current and base period, respectively. As one can note, the footprint factors do not vary with time and, thus, they are not included as a factor of change in the water footprint. The remaining three effects on the right-hand side of Eq. (3) correspond to changes in yields $\left(Y_{i j}^{t}\right)$, crop-mix in counties $\left(A_{i j}^{t}\right)$, spatial distribution of the area harvested across the counties $\left(A_{i}^{t}\right)$ and scale of crop farming $\left(A^{t}\right)$.

\subsection{LMDI model}

The decomposition described in Eq. (3) can be implemented by exploiting different quantitative techniques. For instance, Ang (2005) presented a framework for decomposition based upon the Logarithmic Mean Divisia Index (LMDI). The LMDI is appealing in sense that it ensures residual-free decomposition and is invariant to time reversal, besides satisfying the other desiderata. In our case, we seek to additively factorize the change in the water footprint with respect to the four effects. In this paper, we apply the following calculations for each of the effects in Eq. (3):

$$
\begin{aligned}
& \Delta F_{\text {yield }}=\sum_{i=1}^{I} \sum_{j=1}^{J} \frac{F_{i j}^{T}-F_{i j}^{0}}{\ln F_{i j}^{T}-\ln F_{i j}^{0}} \ln \left(\frac{Y_{i j}^{T}}{Y_{i j}^{0}}\right) ; \\
& \Delta F_{\text {crop }}=\sum_{i=1}^{I} \sum_{j=1}^{J} \frac{F_{i j}^{T}-F_{i j}^{0}}{\ln F_{i j}^{T}-\ln F_{i j}^{0}} \ln \left(\frac{A_{i j}^{T}}{A_{i j}^{0}}\right) ; \\
& \Delta F_{\text {distribution }}=\sum_{i=1}^{I} \sum_{j=1}^{J} \frac{F_{i j}^{T}-F_{i j}^{0}}{\ln F_{i j}^{T}-\ln F_{i j}^{0}} \ln \left(\frac{A_{i}^{T}}{A_{i}^{0}}\right) ; \\
& \Delta F_{\text {scale }}=\sum_{i=1}^{I} \sum_{j=1}^{J} \frac{F_{i j}^{T}-F_{i j}^{0}}{\ln F_{i j}^{T}-\ln F_{i j}^{0}} \ln \left(\frac{A^{T}}{A^{0}}\right) .
\end{aligned}
$$


The underlying idea for decomposition of the water footprint is that LMDI attributes the changes in the aggregate variable, $F_{i j}$ to the four explanatory factors. In this sense, the explanatory variables serve as weights for the decomposition.

The changes in absolute indicators and absolute contributions of the individual effects are meaningful at the aggregate level. However, comparison of the contributions of different factors at the lower levels of aggregation (e.g. crop or county level in our case) is more meaningful. In this case, we normalize the contributions by different factors resulting from Eqs (4)-(7) by the sum of their absolute values. Furthermore, the contributions are negated in case of decrease in the aggregate variable, i.e. water footprint. Thus, the relative contributions by different factors are obtained as follows:

$$
\widetilde{\Delta F_{k}}=\left\{\begin{array}{l}
\Delta F_{k} / \sum_{k}\left|\Delta F_{k}\right|, \Delta F>0 ; \\
-\Delta F_{k} / \sum_{k}|\Delta F|_{k}, \Delta F<0,
\end{array}\right.
$$

where $k$ denotes a certain factor, i.e. $k \in\{$ yield, crop, distribution, scale $\}$.

\subsection{Data used}

The dynamics in water footprint for the major crops cultivated in Lithuania is considered in this paper. The data on crop yields and areas harvested come from Statistics Lithuania (2019). The data are provided for each county. The data cover the period of 2000-2015. The grey and green water footprint factors come from Mekonnen and Hoekstra (2010). The analysis is carried out for the following crops: winter and spring wheat, winter and spring triticale, winter rye, winter and spring barley, oats, buckwheat, mixed cereals, maize, legumes, winter and spring rape, and potatoes.

\section{Results}

As it was defined by the IDA identity outlined in Section 2.2, the changes in the water footprint can be related to multiple factors. In this section, we present both dynamics in the absolute and relative indicators defining the footprint and the results of the IDA. The latter relate the country-wide and regional changes in cropping patterns and yields to changes in the water footprint.

\subsection{Lithuanian agriculture and dynamics in the water footprint}

Lithuanian agriculture has seen serious changes due to shifts in the economic conditions associated with the accession to the European Union (EU) in 2004. The establishment of the direct payments induced increase in the utilized agricultural area as well as changes in the crop structure. Figure 1 presents the dynamics in the area harvested for 2000-2015.

As one can note, the area harvested declined prior to accession the EU. Following 2004, the logged rate of grown in area harvested exceeded the value of $3 \%$. The economic crisis of 2008-2009 also affected agricultural sector in Lithuania and the rate of growth for area harvested became close to null. The period after the economic crisis saw a growth rate of more than $2 \%$ p.a. All in all, area harvested under crops enumerated in Section 2.3 increased from 1.19 million ha up to 1.68 million ha during $2000-2015$. This indicates that the scale of 
crop farming has generally increased in Lithuania. Accordingly, one may expect increase in the water footprint related to the crop farming.

The changes in water footprint can also be driven by structural adjustment. In our model, we consider changes in the distribution of areas harvested across the counties (i.e. regional distribution) and changes in the cropping structure within the counties (i.e. crop-mix). Therefore, we further present the major trends in structural dynamics of crop farming in Lithuania during 2000-2015. Figures 2 and 3 present the dynamics in the structure of are harvested by taking region- and crop-wise approaches, respectively.

The results in Figure 2 suggest that basically each county faced a change in the share in the area harvested during 2000-2015. The counties are arranged in descending order of the change in the share of area harvested. Telšiai, Kaunas, Panevėžys, and Šiauliai Counties saw increasing shares in the national area harvested. At the other end of spectrum, decline in the relative importance was observed for Alytus, Tauragè, Utena, Klaipeda, Vilnius, and Marijampolè Counties.

As one can note, the steepest increase is observed for the largest agricultural producing counties, namely Šiauliai, Panevėžys and Kaunas Counties. Therefore, the increase in the area harvested occurred in areas with factor endowments and established agricultural infrastructure. Given differences in soil quality and the crop-mix across the counties, this kind of structural change may also affect the water footprint of crop farming in Lithuania.

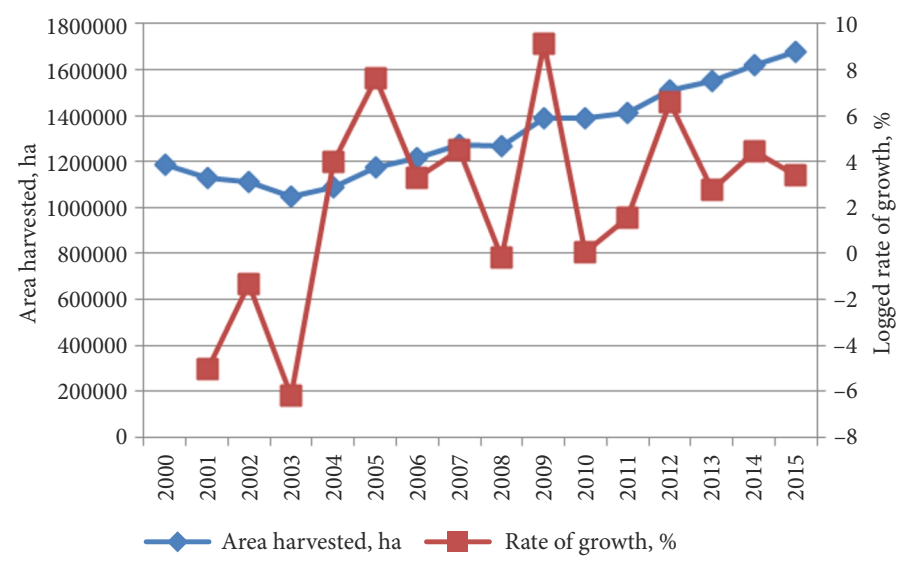

Figure 1. Dynamics in area harvested in Lithuania, 2000-2015

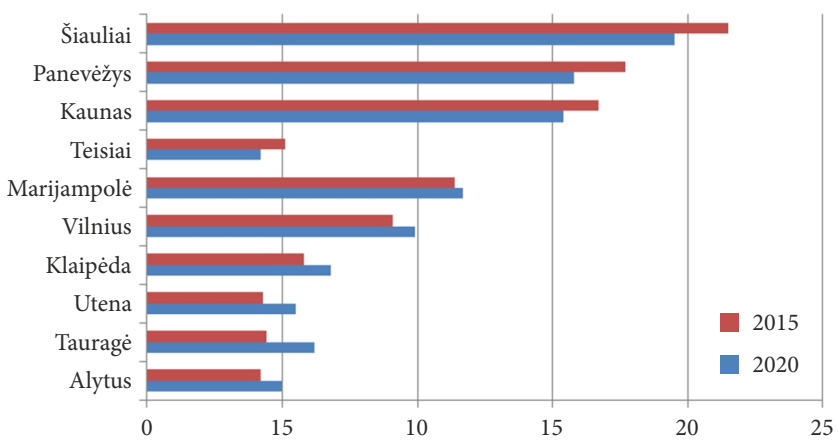

Figure 2. The share of area harvested for each county in Lithuania (\%), 2000 and 2015 


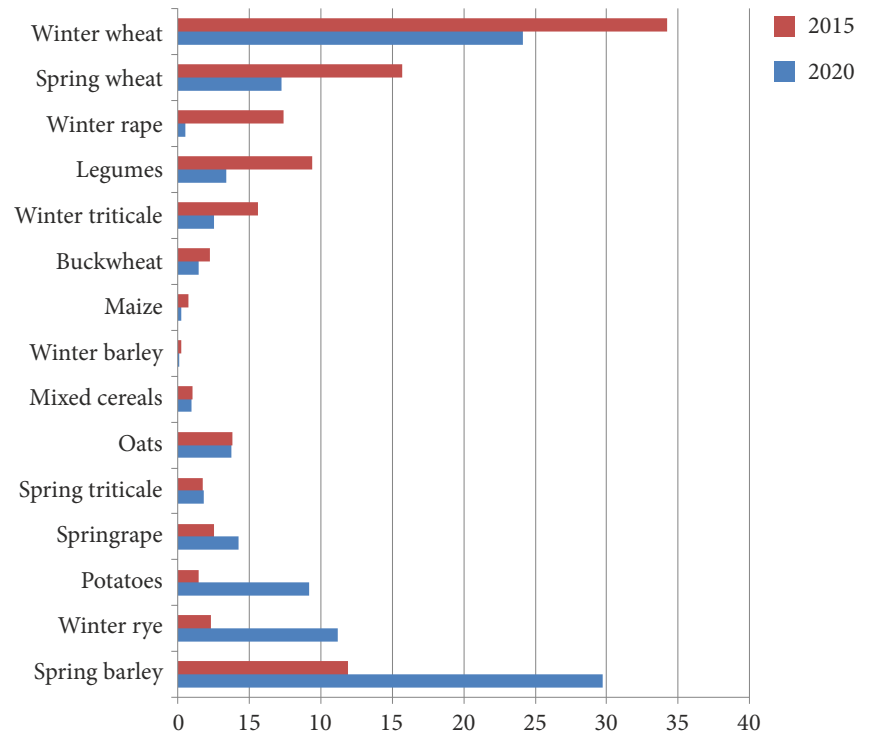

Figure 3. The share of area harvested under different crops in Lithuania (\%), 2000 and 2015

The water footprints can be adjusted at both regional and crop scale. The crop-mix can be impacted by means of support payments. In case the relative income associated with different crops diverges significantly, farmers may opt for corresponding shifts in the crop-mix. The regional distribution of crops and area harvested is mainly related to geoclimatic conditions. The support payments can affect regional distribution of particular crops only in an indirect manner. Thus, management of water footprint is a rather complex issue involving multiple facets of sustainability. Figure 3 presents the dynamics in distribution of the area harvested in between 2000 and 2015 .

The changes in agricultural markets and introduction of the support payments under the CAP have affected the crop-mix in Lithuania. However, the crops have been affected to different extents. The share of area harvested decreased for spring barley, winter rye, potatoes, and spring rape. The relative importance of spring triticale, oats, mixed cereals, and winter barley remained virtually stable. Finally, the share of area harvested went up for maize, buckwheat, winter triticale, legumes, winter rape, spring and winter wheat. The changes in crop-mix are obviously related to dynamics in water footprint as both footprint factors and yield vary across the crops.

Yield determines the water requirements as suggested by Eq. (1). In Lithuania, all the crops saw an increase in yields during 2000-2015. The steepest increase in yield is observed for maize $(6.9 \%$ p.a.). this can be explained by early stage of cultivation of this crop in Lithuania at a wider scale (Figure 3 suggests its share in the total crop-mix is still relatively low). For the rest of the crops, the average annual rates of growth fluctuated around $2 \%$. Winter rye shows the lowest rate of growth of some $0.2 \%$ p.a.

We have shown that there have been both extensive and intensive changes in crop farming in Lithuania. These shifts are often related to changes in the water footprint. In the sequel, we apply the LMDI approach to factorize the changes in the water footprint with respect to the effects outlined in Section 2. 


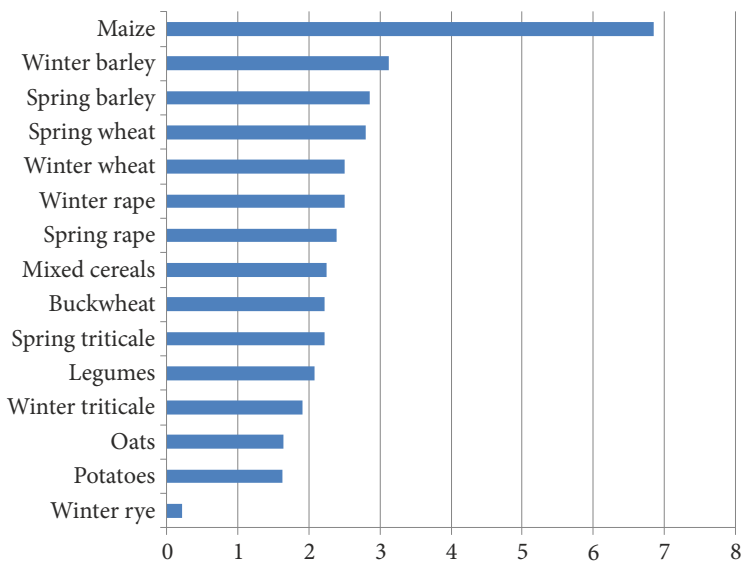

Note: stochastic growth rates are presented.

Figure 4. Changes in crop yields in Lithuania (\%), 2000-2015

\subsection{Decomposition of changes in the water footprint}

Given the trends in crop farming in Lithuania discussed above, the water footprints went up during 2000-2015. The dynamics for the green and grey water footprints are presented in Figures 5 and 6 . As one can note, both of the water footprints followed the same trajectories in general, yet the green footprint showed more variations along the time period considered. In absolute terms, the green water footprint is some 20 times higher than the grey one. The green water footprint increased from 3754 million $\mathrm{m}^{3}$ in 2000 up to 9400 million $\mathrm{m}^{3}$ in 2015 . As regards the grey water footprint, it went up from 123 million $\mathrm{m}^{3}$ to 393 million $\mathrm{m}^{3}$ during the same time period.

The economic results of the crop farming can be quantified by considering the revenue generated. We apply the data from Statistics Lithuania (2019) to calculate the revenue for the crops covered in the analysis. Specifically, selling prices for particular crops are multiplied by the harvest in order to calculate the revenue. The resulting indicators can be compared to the water footprints in order to ascertain whether there has been decoupling between economic activity and the environmental pressures in Lithuanian crop farming. The indices for water footprints and crop revenue are given in Figure 7. As of 2015, the grey water footprint showed a three-fold increase if compared to 2000, whereas the level of the green water footprint stood at some $250 \%$. Meanwhile, the revenue index was $284 \%$ for the same period. This indicates that economic results and the environmental impacts have not been decoupled in Lithuanian crop farming.

The average annual rates of growth vary across the two water footprints. The average annual rate of growth for the green water footprint is $6.3 \%$, whereas the corresponding value for the grey water footprint is $10 \%$. The differences in the levels and changes of the water footprints will be further analysed by means of the LMDI. This will allow isolating the effects specified in Eq. (3) at different levels of aggregation.

The analysis of dynamics in the water footprints is carried out in the chain-linked manner. The results are then aggregated across regions, crop or time periods. This allows identifying the general trends in the growth of the water footprints. 


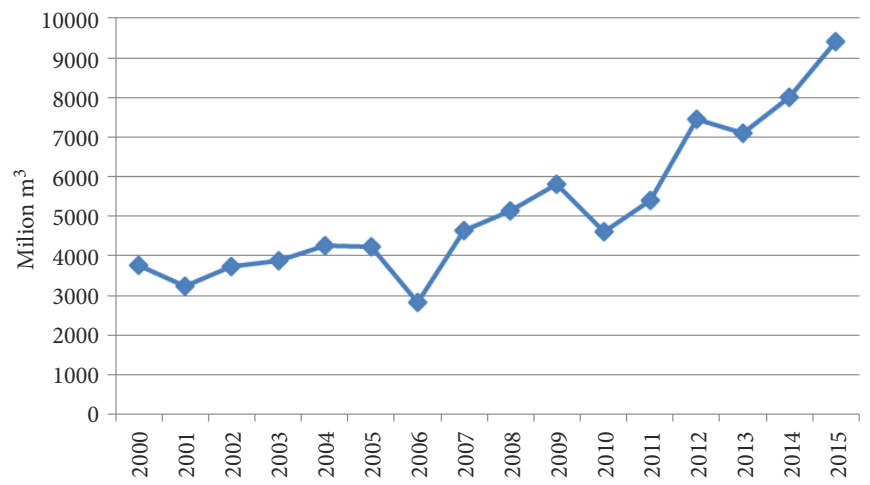

Figure 5. Dynamics in the green water footprint for Lithuanian crop farming, 2000-2015

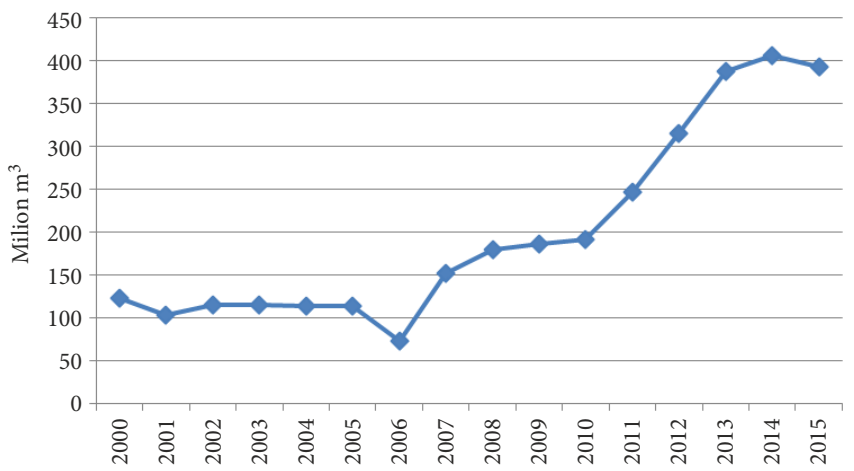

Figure 6. Dynamics in the grey water footprint for Lithuanian crop farming, 2000-2015

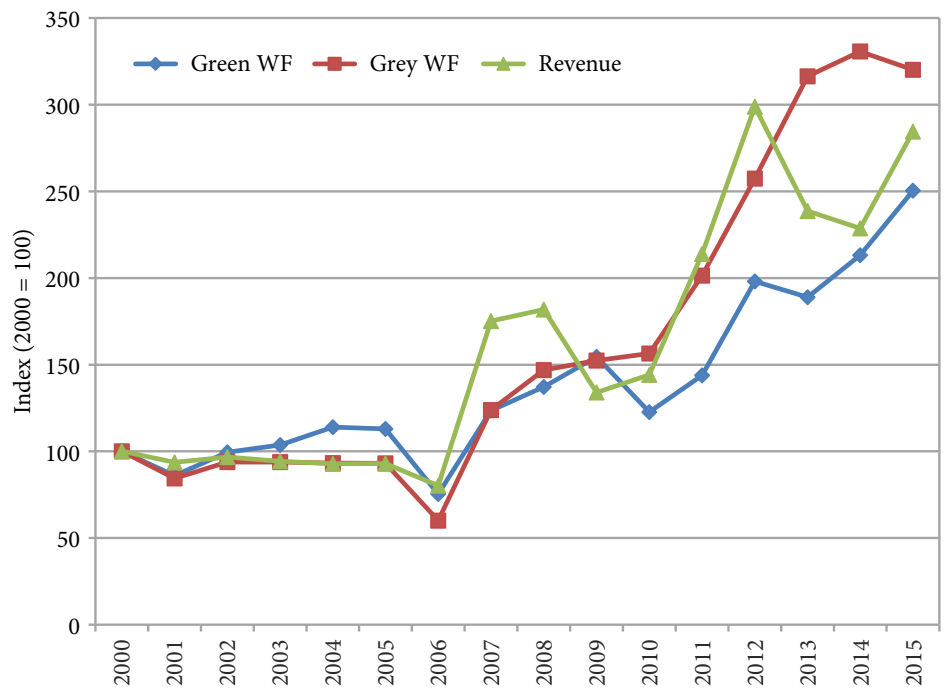

Figure 7. Dynamics in the grey and green water footprints (WFs) and revenue from crop farming in Lithuania, 2000-2015 
Table 1. Decomposition of changes in the water footprints, 2000-2015

\begin{tabular}{|l|c|c|c|c|c|}
\hline $\begin{array}{c}\text { Water } \\
\text { footprint }\end{array}$ & $\begin{array}{c}\text { Scale } \\
\text { effect }\end{array}$ & $\begin{array}{c}\text { Spatial distribution } \\
\text { effect }\end{array}$ & $\begin{array}{c}\text { Crop-mix } \\
\text { effect }\end{array}$ & $\begin{array}{c}\text { Yield } \\
\text { effect }\end{array}$ & $\begin{array}{c}\text { Total } \\
\text { change }\end{array}$ \\
\hline \multicolumn{7}{|c|}{ Absolute level (million $\mathrm{m}^{3}$ ) } \\
\hline Green & 2090 & 30 & 1186 & 2340 & 5647 \\
\hline Grey & 85 & 0 & 139 & 47 & 270 \\
\hline \multicolumn{7}{|c|}{ Relative contribution (\%) } \\
\hline Green & 37 & 1 & 21 & 41 & 100 \\
\hline Grey & 31 & 0 & 51 & 17 & 100 \\
\hline
\end{tabular}

The decomposition based on the LMDI is presented in Table 1. The results are aggregated across crop, regions and years. Thus, the changes in the two types of water footprints are decomposed with respect to the four factors. As one can note, scale effect exerted similar influence on the growth in both types of the water footprints (the contributions of $37 \%$ and $31 \%$ are observed for the green and grey water footprints, respectively). This is obvious given the expansion of area harvested without structural change does not lead to the changes in the aggregate water footprint factor and the "pure" water footprint factors remain stable across regions, crops and time periods.

The contribution of the spatial distribution effect is virtually nil for both types of the water footprints. This suggests the changes in the aggregate crop yields and, hence, aggregate water footprint factors did not change due to the shifts in the distribution of the harvested across the counties. Crop-mix and yield effects appeared as the major ones. However, the extent of their contribution varies across the two types of the water footprints. Specifically, the yield effect played the key role in promoting the green water footprint (contribution of $41 \%$ to the overall growth in the water footprint), whereas the crop-mix effect dominated the other effects in the case of grey water footprint (contribution of 51\%). This indicates cropmix is much more decisive for the dynamics in the grey water footprints as the amounts of agrochemicals applied vary across the crops and the impact of yield change remains negligible. The contribution of changes in the crop-mix towards the growth in the green water footprint is $21 \%$. As regards the contribution of the yield effect to the growth in the grey water footprint, the value of $17 \%$ is observed. We further decompose the aggregate results presented in Table 1 with regards to different dimensions of the IDA model. Figure 8 presents the decomposition of the change in the green water footprint for different time periods.

The decomposition results outlined in Figure 8 suggest that the yield effect pushed the green water footprint down in 2005-2006, 2009-2010 and 2012-2013. These cases are related to unfavourable climatic conditions. The scale effect is directly related to dynamics in the area harvested. The positive contribution to the green water footprint was observed throughout the period covered albeit its absolute contribution varied. The crop-mix effect remained positive for much of the research period indicating that there have been shifts towards waterintensive crops in Lithuanian crop farming. We further decompose the changes in the green water footprint in order to identify the patterns associated with different crops and regions.

The decomposition of changes in the green water footprint across crops is presented in Figure 9. The results are obtained by applying Eq. (8). The three crops show a decrease in the green carbon footprint, namely winter barley, spring barley and potatoes. As regards the crop with increasing water footprints, they were mostly affected by increasing scale and yields. 


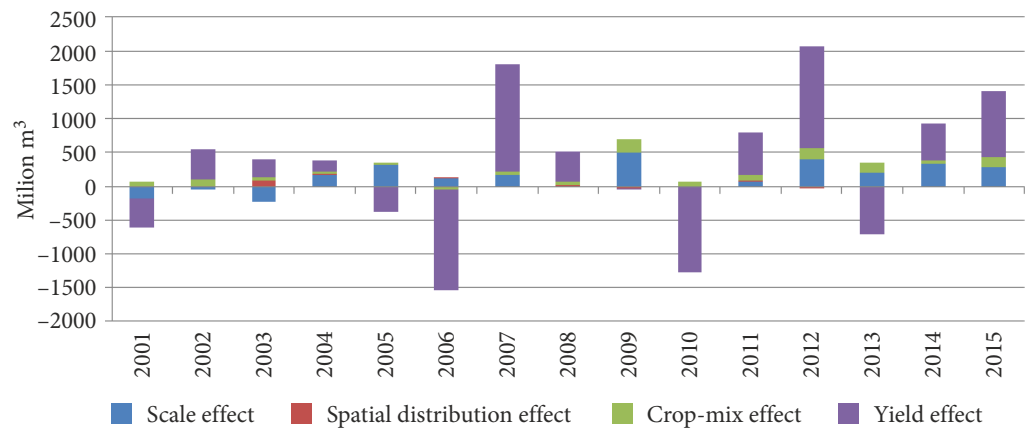

Note: the current year is provided in the figure.

Figure 8. Decomposition of the green water footprint across different time periods, 2000-2015

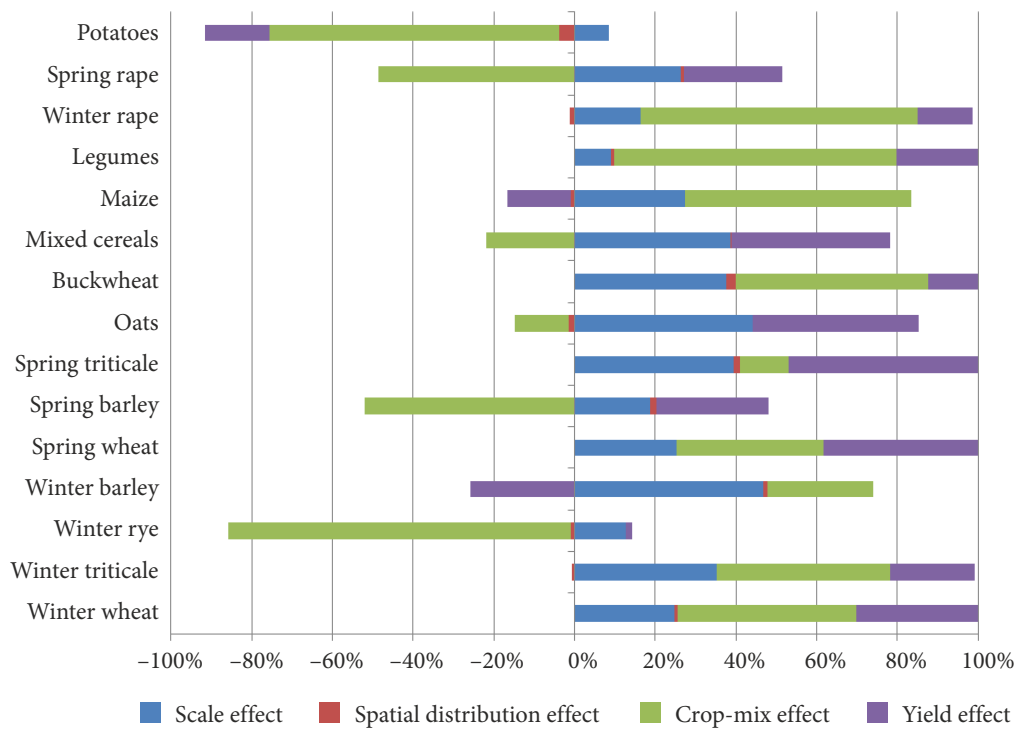

Note: the relative contributions were obtained by applying Eq. (8).

Figure 9. Decomposition of changes in the green water footprint across crops, 2000-2015

The crop-mix affected the change in the water footprint differently depending on the direction of change in the shares of different crops. The negative yield effects are observed for potatoes, maize and winter barley. Indeed, these crops showed upward trends in yields (Figure 4). Anyway, actual fluctuations in yields resulted in overall negative contribution towards change in the water footprint for those crops.

The region-wise decomposition is presented in Figure 10. Obviously, the distribution effect plays a more important role on the latter perspective. Correspondingly to results in Figure 2, the steepest decline in the green water footprint due to the distribution effect is observed for Taurage and Alytus Counties. The crop-mix effect contributed to growth in the water footprint across all of the counties covered in the analysis. This suggests that the changes in the crop-mix were oriented towards water-intensive crops independently of the county considered. Yield effect was equally important across the counties with exception of Alytus County. 
The grey water footprint is important in that it is related to non-point pollution resulting from the use of agrochemicals. The crop output should be compared to the grey water footprint in order to gain insights into environmental sustainability of the crop farming. Therefore, we further decompose the dynamics in the grey water footprint. As it was the case with the green water footprint, we look into decomposition across time periods, crops and counties. Figures 11 and 12 present the results. By comparing Figures 5 and 6, one can note that the increase in the grey water footprint took place 2009-2013, whereas the later period marked stagnation. In this regard, it is important to identify the driving forces behind these patterns.

Note that the decomposition at the crop ant county levels features certain common elements across the two types of the water footprint. As regards the region-wise decomposition, the factors entering the IDA identity are the same for both types of the water footprint with exception of the water footprint factor. Turning to region-wise decomposition, the relative effects of the spatial distribution remain the same across the two types of the footprints.

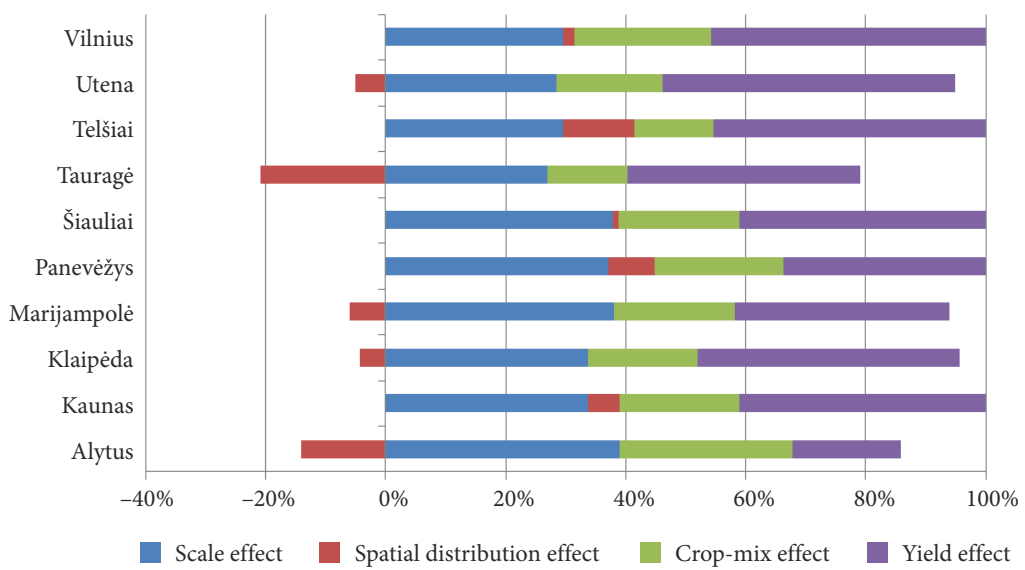

Note: the relative contributions were obtained by applying Eq. (8).

Figure 10. Decomposition of changes in the green water footprint across counties, 2000-2015

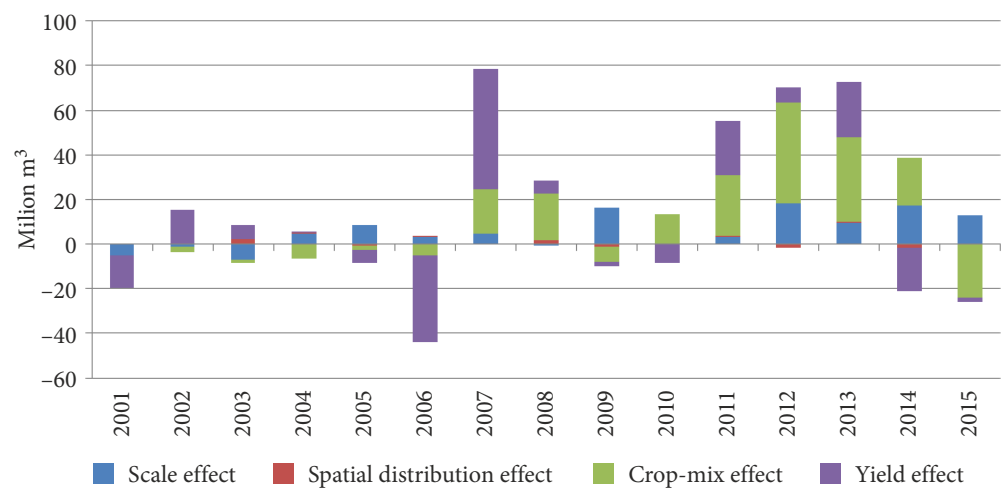

Note: the current year is provided in the figure.

Figure 11. Decomposition of the grey water footprint across different time periods, 2000-2015 


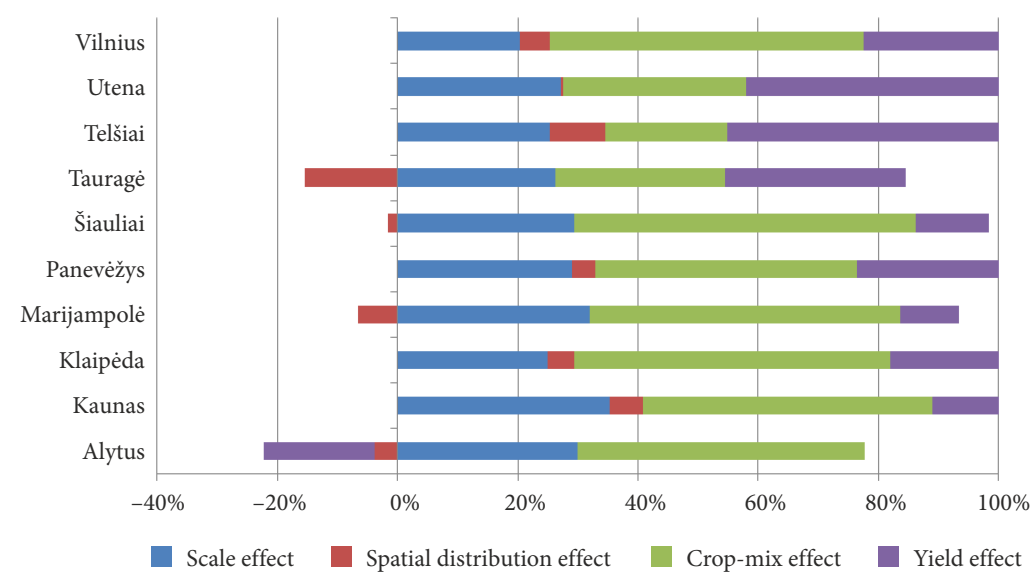

Note: the relative contributions were obtained by applying Eq. (8).

Figure 12. Decomposition of changes in the grey water footprint across counties, 2000-2015

The fluctuations in grey water footprint were negligible up until 2005. The drought in 2006 pushed the grey water footprint down. The following year 2007 saw a rebound in the water footprint which exceeded the decline in the previous period. In these two instances, the yield effect played the most important role. The period following year 2006 also saw an increase in the absolute contribution of the crop-mix effect. For most of the years, the latter effect remained positive with exceptions for 2008-2009 and 2014-2015. The yield effect appeared as an important contributor in the absolute terms during 2010-2013, yet the period of 2013-2014 a decline the water footprint due to the latter effect. Scale effect remained rather stable throughout 2011-2015. The case of 2014-2015 shows that changes in crop-mix can completely offset the effect of scale change. These results suggest crop-mix adjustments may mitigate the growth in the grey water footprint.

The crop-wise decomposition of changes in the grey water footprint is corresponds to the one given in Figure 9. This is due to the fact that at the crop level the changes in the water footprint are driven by the same effects with exception of changes in the footprint factors. However, our model assumes constant footprint factors which rules out the possibility of the latter effect. Obviously, the absolute values of the individual affects vary across the grey and green water footprints.

The spatial effect is slightly different from that observed for the green water footprint across the counties. This is due to the relative differences in the green and grey water footprint factors associated with different crops. As one can note, the negative effects of the spatial distribution observed for green water footprint in Utena, Marijampole and Klaipeda went up in the case of the grey water footprint if compared to the green water footprint. Notably, Alytus county shows a decline in the grey water footprint due to the yield effect which is not observed for the green water footprint. This is also related to different levels of grey water footprint factors associated with different crops. 


\section{Conclusions}

The water economics has become increasingly important in the European Union and the other regions due to the climate change and sustainability concerns. This paper developed a framework for assessing the water-economy-water nexus in the crop farming of Lithuania. The LMDI-based index decomposition analysis model was set up to identify the driving forces behind the changes in the water footprint of Lithuanian crop farming. Given the recent developments of sector induced by the EU Common Agricultural Policy, among other factors, the analysis allowed quantifying the effects of scale, spatial distribution of agricultural area, crop-mix and yields on the dynamics in the water footprints. Obviously, technological, economic and environmental conditions affected the aforementioned factors. The index decomposition analysis model allowed to isolate particular effects and aggregate them across counties and crops.

The expansion of the crop farming in Lithuania began following the accession the European Union. Besides extensive development, the public support allowed for improvements in cropping practices. As a result, the harvest went up not only because of the scale effect, but also due to structural changes (in the sense of areas harvested and crop-mix) and pure yield growth. The average annual rate of growth for the green and grey water footprints were $6.3 \%$ and $10 \%$ respectively. Growth in the crop revenue did not diverge from the water footprint. This indicates that economic results of the crop farming are still coupled with the water footprint. In this regard, Lithuanian crop farming still needs further improvements in sustainability.

The LMDI was applied in order to decompose than changes in the green and grey water footprints for crop farming in Lithuania. Due to the expansion of the areas harvested, the scale effect appeared as an important driver of growth in green and grey water footprints with contributions of $37 \%$ and $31 \%$, respectively. The shifts in spatial distribution of area harvested virtually had no influence on the dynamics in either of the water footprints. Thanks to higher degree of differences in grey water footprint factors associated with different crops (if contrasted to those for the green water footprint), the crop-mix effect was much higher for the grey water footprint (51\% over the period of 2000-2015) than it was the case for the green water footprint $(21 \%)$. The yield growth induced growth in both green and grey water footprints.

The mitigation of the growth in the grey water footprint is required I order to increase the sustainability of Lithuanian crop farming. The results indicate this can be done by adjusting the crop-mix in Lithuania. Indeed, the Common Agricultural Policy has caused certain shifts in the crop-mix in Lithuania. Specifically, the areas sown under cereals have increased. Policy makers should take the dynamics in the water footprint into account when designing the public support policies. For this end, an integrated framework relating economic and environmental indicators should be further developed. The index decomposition analysis can serve as a means for obtaining the isolated effects of different factors in the dynamics in the water footprint.

The index decomposition analysis identity employed in this research could be extended towards different directions. The revenue indicators could be directly related to the water footprint thus extending the scope of the analysis. The dimension of food security could be taken when accounting for the intake of calories and domestic consumption of agricultural products. Besides, the other types of footprints (ecological footprints) could be applied. The 
present research is also limited in that it applied the aggregate data (e.g., country-wide average yields). Further research could also look at the effects of crop farming on commercial farms of different size classes.

\section{Acknowledgements}

This paper is supported by National Natural Science Foundation of China (No. 71671165), National Social Science Fund of China (No. 16BTJ026) and Statistical Scientific Research Project of China (No. 2018LY80). This project has received funding from European Social Fund (project No 09.3.3-LMT-K-712-01-0007) under grant agreement with the Research Council of Lithuania (LMTLT). We would like to thank Mette Asmild, Jens Leth Hougaard, Irena Kriščiukaitienè, Rasa Melnikienè, Vida Dabkienè, Justas Štreimikis and Mindaugas Butkus for research assistance.

\section{References}

Ang, B. W. (2005). The LMDI approach to decomposition analysis: A practical guide. Energy Policy, 33(7), 867-871. https://doi.org/10.1016/j.enpol.2003.10.010

Ang, B. W. (2015). LMDI decomposition approach: A guide for implementation. Energy Policy, 86, 233-238. https://doi.org/10.1016/j.enpol.2015.07.007

Arto, I., Andreoni, V., \& Rueda-Cantuche, J. M. (2016). Global use of water resources: A multiregional analysis of water use, water footprint and water trade balance. Water Resources and Economics, 15, 1-14. https://doi.org/10.1016/j.wre.2016.04.002

Aznar-Sánchez, J. A., Belmonte-Ureña, L. J., Velasco-Muñoz, J. F., \& Manzano-Agugliaro, F. (2018). Economic analysis of sustainable water use: A review of worldwide research. Journal of Cleaner Production, 198, 1120-1132. https://doi.org/10.1016/j.jclepro.2018.07.066

Aznar-Sánchez, J. A., Velasco-Muñoz, J. F., Belmonte-Ureña, L. J., \& Manzano-Agugliaro, F. (2019). The worldwide research trends on water ecosystem services. Ecological Indicators, 99, 310-323. https://doi.org/10.1016/j.ecolind.2018.12.045

Bae, J., \& Dallerba, S. (2018). Crop production, export of virtual water and water-saving strategies in Arizona. Ecological Economics, 146, 148-156. https://doi.org/10.1016/j.ecolecon.2017.10.018

Cai, X., Wallington, K., Shafiee-Jood, M., \& Marston, L. (2018). Understanding and managing the foodenergy-water nexus-opportunities for water resources research. Advances in Water Resources, 111, 259-273. https://doi.org/10.1016/j.advwatres.2017.11.014

Chaudhry, A. M. (2018). Improving on-farm water use efficiency: Role of collective action in irrigation management. Water Resources and Economics, 22, 4-18. https://doi.org/10.1016/j.wre.2017.06.001

Chaudhry, A. M., \& Barbier, E. B. (2013). Water and growth in an agricultural economy. Agricultural Economics, 44(2), 175-189. https://doi.org/10.1111/agec.12002

Dainys, J., Jakubavičiūtè, E., Gorfine, H., Pūtys, Ž., Virbickas, T., Jakimavičius, D., Šarauskienė, D., Meilutytė-Lukauskiene, D., Povilaitis, A., Bukantis, A., Kažys, J., \& Ložys, L. (2019). Predicted climate change effects on European perch (Perca fluviatilis L.) - A case study from the Curonian Lagoon, south-eastern Baltic. Estuarine, Coastal and Shelf Science, 221, 83-89. https://doi.org/10.1016/j.ecss.2019.03.020

D’Ambrosio, E., De Girolamo, A. M., \& Rulli, M. C. (2018). Assessing sustainability of agriculture through water footprint analysis and in-stream monitoring activities. Journal of Cleaner Production, 200, 454-470. https://doi.org/10.1016/j.jclepro.2018.07.229 
De Girolamo, A. M., Miscioscia, P., Politi, T., \& Barca, E. (2019). Improving grey water footprint assessment: Accounting for uncertainty. Ecological Indicators, 102, 822-833. https://doi.org/10.1016/j.ecolind.2019.03.040

Drysdale, K. M., \& Hendricks, N. P. (2018). Adaptation to an irrigation water restriction imposed through local governance. Journal of Environmental Economics and Management, 91, 150-165. https://doi.org/10.1016/j.jeem.2018.08.002

Fedulova, S., Komirna, V., Naumenko, N., \& Vasyliuk, O. (2019). Regional development in conditions of limitation of water resources: correlation interconnections. Montenegrin Journal of Economics, 14(4), 57-68. https://doi.org/10.14254/1800-5845/2018.14-4.4

Hoekstra, A. Y., Chapagain, A. K., Aldaya, M. M., \& Mekonnen, M. M. (2011). The water footprint assessment manual. Setting the global standard. Earthscan from Routledge.

Li, Y., Lu, L., Tan, Y., Wang, L., \& Shen, M. (2017). Decoupling water consumption and environmental impact on textile industry by using water footprint method: A case study in China. Water, 9(2), 124. https://doi.org/10.3390/w9020124

Lin, C., Jeng, S., Tseng, M., \& Wong, W. P. (2019). Sustainable development for zero-wastewater-discharge reproduction planning under quantitative and qualitative information. Management of Environmental Quality, 30(5), 1114-1131. https://doi.org/10.1108/MEQ-12-2018-0213

McCarl, B. A., \& Hertel, T. W. (2018). Climate change as an agricultural economics research topic. Applied Economic Perspectives and Policy, 40(1), 60-78. https://doi.org/10.1093/aepp/ppx052

Mekonnen, M. M., \& Hoekstra, A. Y. (2010). The green, blue and grey water footprint of crops and derived crop products (Value of Water Research Report Series No. 47). UNESCO-IHE, Delft, the Netherlands. http://www.waterfootprint.org/Reports/Report47-WaterFootprintCrops-Vol1.pdf

Miao, Z., Baležentis, T., Tian, Z., Shao, S., Geng, Y., \& Wu, R. (2019). Environmental performance and regulation effect of China's atmospheric pollutant emissions: Evidence from "Three Regions and Ten Urban Agglomerations". Environmental and Resource Economics, 74, 211-242. https://doi.org/10.1007/s10640-018-00315-6

Miglietta, P., Morrone, D., \& De Leo, F. (2018). The water footprint assessment of electricity production: An overview of the economic-water-energy nexus in Italy. Sustainability, 10(1), 228. https://doi.org/10.3390/su10010228

Miglietta, P., Toma, P., Fanizzi, F., De Donno, A., Coluccia, B., Migoni, D., Bagordo, F., \& Serio, F. (2017a). A grey water footprint assessment of groundwater chemical pollution: Case study in Salento (southern Italy). Sustainability, 9(5), 799. https://doi.org/10.3390/su9050799

Miglietta, P. P., De Leo, F., \& Toma, P. (2017b). Environmental Kuznets curve and the water footprint: An empirical analysis. Water and Environment Journal, 31(1), 20-30. https://doi.org/10.1111/wej.12211

Papadimitriou, L., D’Agostino, D., Borg, M., Hallett, S., Sakrabani, R., Thompson, A., \& Knox, J. (2019). Developing a water strategy for sustainable irrigated agriculture in Mediterranean island communities - Insights from Malta. Outlook on Agriculture, 48(2), 143-151. https://doi.org/10.1177/0030727019841060

Richard, A., Casagrande, M., Jeuffroy, M. H., \& David, C. (2018). An innovative method to assess suitability of Nitrate Directive measures for farm management. Land Use Policy, 72, 389-401. https://doi.org/10.1016/j.landusepol.2017.12.059

Rosegrant, M. W., Ringler, C., Zhu, T., Tokgoz, S., \& Bhandary, P. (2013). Water and food in the bioeconomy: Challenges and opportunities for development. Agricultural Economics, 44(s1), 139-150. https://doi.org/10.1111/agec.12058 
Schönhart, M., Trautvetter, H., Parajka, J., Blaschke, A. P., Hepp, G., Kirchner, M., Mitter, H., Schmid, E., Strenn, B., \& Zessner, M. (2018). Modelled impacts of policies and climate change on land use and water quality in Austria. Land use Policy, 76, 500-514.

https://doi.org/10.1016/j.landusepol.2018.02.031

Sears, L., \& Lawell, C. Y. L. (2019). Water management and economics. The Routledge Handbook of Agricultural Economics, 269-284. https://doi.org/10.4324/9781315623351-16

Serban, A. C., Aceleanu, M. I., \& Saseanu, A. S. (2017) Constraints of transition to ecological agriculture in a sustainable development society. Romanian Perspective. Transformations in Business \& Economics, 16, 56-73.

Song, M., Fisher, R., \& Kwoh, Y. (2019). Technological challenges of green innovation and sustainable resource management with large scale data. Technological Forecasting and Social Change, 144, 361-368. https://doi.org/10.1016/j.techfore.2018.07.055

Statistics Lithuania. (2019). Indicator Database. Retrieved April 1, 2019, from https://osp.stat.gov.lt/ statistiniu-rodikliu-analize\#/

Tian, H., Lu, C., Pan, S., Yang, J., Miao, R., Ren, W., Yu, Q., Fu, B., Jin, F.-F., Lu, Y., Melillo, J., Ouyang, Z., Palm, \& C., Reilly, J. (2018). Optimizing resource use efficiencies in the food-energy-water nexus for sustainable agriculture: From conceptual model to decision support system. Current Opinion in Environmental Sustainability, 33, 104-113. https://doi.org/10.1016/j.cosust.2018.04.003

Toma, P., Miglietta, P. P., Zurlini, G., Valente, D., \& Petrosillo, I. (2017). A non-parametric bootstrapdata envelopment analysis approach for environmental policy planning and management of agricultural efficiency in EU countries. Ecological Indicators, 83, 132-143. https://doi.org/10.1016/j.ecolind.2017.07.049

Tsolakis, N., Srai, J., \& Aivazidou, E. (2018). Blue water footprint management in a UK poultry supply chain under environmental regulatory constraints. Sustainability, 10(3), 625.

https://doi.org/10.3390/su10030625

UN-Water. (2018). The United Nations World Water Development Report 2018: Nature-Based Solutions for Water. United Nations Educational, Scientific and Cultural Organization, Paris, France. http://unesdoc.unesco.org/images/0026/002614/261424e.pdf

Velasco-Muñoz, J., Aznar-Sánchez, J., Belmonte-Ureña, L., \& López-Serrano, M. (2018a). Advances in water use efficiency in agriculture: A bibliometric analysis. Water, 10(4), 377. https://doi.org/10.3390/w10040377

Velasco-Muñoz, J., Aznar-Sánchez, J., Belmonte-Ureña, L., \& Román-Sánchez, I. (2018b). Sustainable water use in agriculture: A review of worldwide research. Sustainability, 10(4), 1084. https://doi.org/10.3390/su10041084

Wang, J., Ma, Y., \& Collins, A. R. (2019). Measuring benefits of rural-to-urban water transfer: A case study from Puyang River basin, China. Chinese Journal of Population Resources and Environment, 17(4), 352-358. https://doi.org/10.1080/10042857.2019.1613628

$\mathrm{Xu}, \mathrm{W}$., \& Lowe, S. E. (2018). An integrated analysis of the effects of local water institutions on irrigated agriculture outcomes in the arid western United States. Applied Economics, 50(15), 1761-1776. https://doi.org/10.1080/00036846.2017.1374539

Xu, Y., Huang, K., Yu, Y., \& Wang, X. (2015). Changes in water footprint of crop production in Beijing from 1978 to 2012: A Logarithmic Mean Divisia Index decomposition analysis. Journal of Cleaner Production, 87, 180-187. https://doi.org/10.1016/j.jclepro.2014.08.103

Zhao, C., \& Chen, B. (2014). Driving force analysis of the agricultural water footprint in China based on the LMDI method. Environmental Science \& Technology, 48(21), 12723-12731. https://doi.org/10.1021/es503513z 
Zhao, C., Chen, B., Hayat, T., Alsaedi, A., \& Ahmad, B. (2014). Driving force analysis of water footprint change based on extended STIRPAT model: Evidence from the Chinese agricultural sector. Ecological Indicators, 47, 43-49. https://doi.org/10.1016/j.ecolind.2014.04.048

Zhao, X., Tillotson, M. R., Liu, Y. W., Guo, W., Yang, A. H., \& Li, Y. F. (2017). Index decomposition analysis of urban crop water footprint. Ecological Modelling, 348, 25-32. https://doi.org/10.1016/j.ecolmodel.2017.01.006

Zhuo, L., Mekonnen, M. M., \& Hoekstra, A. Y. (2016). The effect of inter-annual variability of consumption, production, trade and climate on crop-related green and blue water footprints and interregional virtual water trade: A study for China (1978-2008). Water Research, 94, 73-85. https://doi.org/10.1016/j.watres.2016.02.037

Zilberman, D. (2014). The economics of sustainable development. American Journal of Agricultural Economics, 96(2), 385-396. https://doi.org/10.1093/ajae/aat075

Zilberman, D., Gordon, B., Hochman, G., \& Wesseler, J. (2018). Economics of sustainable development and the bioeconomy. Applied Economic Perspectives and Policy, 40(1), 22-37.

https://doi.org/10.1093/aepp/ppx051 